\title{
Novos rumos para a sociedade anônima. As emprêsas no contexto social.
}

\author{
Oscar Barreto Filho \\ Catedratico de Direito Comercial na Faculdade \\ de Direito da Universidade de São Paulo.
}

A sociedade política, já Aristóteles afirmava, é uma sociedade complexa, constituída por sociedades menores. Numerosos e variados grupos sociais se interpõem entre os indivíduos e o Estado: as famílias e os grupos de base territorial, profissional ou ideológica. Os indivíduos se integram na sociedade política através de corpos intermediários, e isto também acontece no campo econômico.

A atividade econômica, que se destina à satisfação das necessidades humanas de bens e serviços, é desenvolvida no quadro de corpos intermediários organizados com essa finalidade.

O organismo especificamente incumbido do exercício da atividade econômica é a emprêsa, num sentido amplo, ou melhor, são as emprêsas. Isto porque a emprêsa se reveste de formas múltiplas que, originadas na sucessão histórica, hoje coexistem.

Neste sentido largo, emprêsas são as unidades de produção, abrangendo não sòmente as emprêsas comerciais do setor capitalista (sentido estrito), como também as explorações dos setôres não capitalistas. Assim, pode-se falar em emprêsas individuais ou coletivas (as sociedades), emprêsas comerciais ou rurais, emprêsas capitalistas ou cooperativas, emprêsas privadas ou públicas. 
Seja qual fôr a destinação do proveito resultante da atividade econômica, tôdas as emprêsas apresentam em comum sua finalidade produtiva, mediante o emprêgo de normas organizacionais e operacionais adequadas. 亡 comum dizer-se que o lucro é a finalidade específica da atividade empresarial, o que não se afigura correto. 0 lucro é antes um resultado da atividade empresarial, constitui indice da vitalidade e condição de eficiência e não atributo definidor da emprêsa.

Tal é a importância que assume a emprêsa no quadro econômico, projetando-se nos cenários social e político, que já se pergunta, com RiperT, se não chegou a hora de conferir personalidade juridica à emprêsa, tornando-a sujeito de direitos e de obrigações, distinto da pessoa do empresário. A personalização da emprêsa constitui matéria de amplo debate doutrinário, principalmente em direito do trabalho, porém não está consagrada pela lei. O tema continua em elaboração e a solução ainda será obra do futuro.

Em nossos dias, observa-se o esmagamento da emprêsa individual pela emprêsa coletiva, fenômeno mais acentuado no setor mercantil, mas que também pode ser notado em setôres tradicionalmente individualistas, como o das profissões liberais e o do artesanato. A independência econômica torna-se muitas vêzes um handicap na sociedade contemporânea. A dependência salarial, atenuada pelas garantias outorgadas pela legislação social, apresenta às vêzes mais vantagens do que a autonomia laboral. Em conseqüência, há a tendência para a absorção dos trabalhadores autônomos pelas emprêsas societárias.

No setor comercial ou mercantil, que tem por escôpo a produção e circulação de bens e serviços destinados ao mercado, predominam as sociedades comerciais, mais precisamente as sociedades anônimas. A crescente complexidade dos processos tecnológicos e dos mecanismos econômicos peculiares à economia de massa obriga à adoção de formas cada vez mais complexas de organização da 
produção, repercutindo necessàriamente na estrutura juridica das emprêsas.

O desenvolvimento das sociedades comerciais e, mais particularmente, das sociedades anônimas, o espetáculo de sua permanência, em contraste com a transitoriedade dos sêres humanos, levam a distinguir, na vida dos negócios, a emprêsa e o empresário.

A emprêsa nasce, geralmente, da imaginação e da energia de um homem empreendedor, com quem ela na origem se confunde e do qual conserva muitas vêzes o nome e o estilo. Entretanto, os homens passam, os capitais se transferem de um para outro titular, a própria atividade se modifica, mas a emprêsa, adaptando-se embora às novas condições do meio, continua empós de seu destino próprio (Paul Didier, Droit commercial, 1970, pág. 215).

Como já assinalamos de outra feita, o próprio esfôrço desenvolvido pelo empresário, no sentido de atribuir à emprêsa uma consistência objetiva, leva ao resultado de que a pessoa do titular se vá apagando gradualmente na consciência do grande público, para dar lugar à presença mais firme e mais estável da emprêsa. Daí a tendência natural, que comumente se nota, de referir à emprêsa aquêles direitos, aquelas manifestações de atividade que, de fato, são concernentes ao empresário. Emprêsa e empresário se correlacionam, embora permaneçam irredutíveis um ao outro, como têrmos que se exigem reciprocamente numa relação de complementaridade, e só encontram seu significado pleno na unidade da relação que constituem (nossa Teoria do Estabelecimento Comercial, São Paulo, 1969, n. 86).

A idéia-força de emprêsa projeta-se na realidade de nossos dias, principalmente sob a forma da sociedade anônima, que extrai seus capitais de tantos bôlsos que nâo se sabe mais exatamente a quem ela pertence e até parece haver caído no domínio público (PAul Didier, obra citada). 
De tôdas as formas de emprêsa, a da sociedade anônima é a mais adequada à moderna economia de massa. Basta lembrar que a estrutura da sociedade anônima é bàsicamente a forma instrumental de organização utilizada pelas emprêsas públicas ou cooperativas, até mesmo nos países de economia planificada de Estado.

\section{A “corporation" norte-americana.}

Rica e variada é a problemática da sociedade anônima, envolvendo aspectos jurídicos e econômicos, institucionais e operacionais, tributários e trabalhistas.

Em excelente coletânea de estudos publicados sob os auspícios da Universidade de Harvard, Edward Mason reune as manifestações dos mais autorizados especialistas norte-americanos na matéria, situando o estado atual das questóes sôbre o papel da corporation na sociedade moderna (EDward S. Mason, The corporation in modern society, Cambridge, 1966).

A sociedade anônima está hoje no centro de um vasto debate, que envolve o próprio futuro do nosso sistema econômico.

Como assinala Adolf BerLe Jr., a sociedade anônima norte-americana não é produto de dogmas ou doutrinas, constitui ao contrário o resultado de um crescimento orgânico. Fêz fortuna nos anos 30 o livro publicado em colaboração por BERLE e MEANs - The modern corporation and private property - hoje traduzido em tôdas as línguas, no qual vem afirmada a natureza institucional e criadora da sociedade anônima, determinando até a modificação do conceito de propriedade privada.

Hoje em dia, o papel da sociedade anônima não é puramente econômico, mas interfere na própria organização política, em virtude de originar uma fonte real de poder (o chamado poder econômico, que se confronta com as 
fontes formais de poder previstas na Constituição. No plano social, a redistribuição da renda ensejada pela massiça participação da poupança popular nos capitais das sociedades anônimas, deixam entrever uma "eventual socialização não-estatista de seus lucros" (a expressão é de BERLE).

A abertura das emprêsas à poupança popular nos Estados Unidos propiciou a chamada democratização do capital e a ascenção dos técnicos ao comando das emprêsas, caracterizando uma verdadeira revolução tecnocrática (a inanagerial revolution, de BuRnHAM).

Em novo livro publicado em 1954, - The 20 th century capitalist revolution - AdOLF BerLe JR. mostrava que os modernos executivos das corporations não se limitam a dirigílas com o objetivo de alcançar o máximo rendimento, mas, de fato e de direito, são os administradores de um sistema comunitário.

A preocupação e o interêsse revelados na grande república norte-americana pelos problemas das sociedades anônimas comprovam que os diretores das corporations devem ter tido, nas últimas décadas, "uma visão no caminho de Damasco". Diz Berle, sem rodeios, que os princípios e as práticas das grandes emprêsas atualmente lhe parecem muito mais responsáveis, compreensivos e honestos do que em 1929. Ainda bem que a evolução se fêz no bom sentido.

As mudancas introduzidas na estrutura de poder e de comando da moderna sociedade industrial, na qual os centros de decisão vêm paulatinamente se transferindo dos proprietários de ações para os planejadores e técnicos, integrantes da tecnoestrutura, levaram GaILbRath a delinear a existência do Nôvo Estado Industrial, destinado a substituir a economia de mercado, que governa os interêsses capitalistas. $O$ quadro dessas transformações são justamente as grandes companhias (John Kenneth Galbraith, $O$ Nôvo Estado Industrial, trad. brasil., 1968). 


\section{A sociedade anônima do amanhã.}

Também nos países europeus se observa a reformulação das idéias e dos conceitos sôbre as sociedades anônimas, refletindo a tendência de adaptá-las às novas condições sociais. Reflexos dessas idéias encontram-se nos novos textos legais, como a lei alemã sôbre as sociedades por ações (Aktiengesetz) de 6 de setembro de 1965 e a lei francesa sôbre as sociedades comerciais de 24 de julho de 1966 .

Com apoio na doutrina jurídica alemã (Muller-Erzbach, Krause, Ballerstedt) podem ser salientadas três ordens de fenômenos econômico-sociais, que se traduzem em impulsos evolutivos no sentido de modificar a estrutura jurídica da sociedade anônima:

a) - A progressiva separação entre a propriedade $\mathrm{e}$ a gestão da emprêsa, que se nota principalmente no quadro das grandes companhias, onde se observa a constituição de um centro autônomo de interêsses na própria emprêsa, distintos dos interêsses particulares dos acionistas.

Recorde-se, a propósito, a frase atribuída a um diretor do Norddeutscher Lloyd, que teria declarado, no decorrer de um debate, ser objeto de sua sociedade, não distribuir lucros aos acionistas, mas sim cruzar o Reno com os seus navios.

b) - A gradativa afirmação de um direito de co-gestão atribuído aos colaboradores da emprêsa, de modo a limitar a liberdade dos proprietários dos meios de produção.

Alguns países, como a República Federal Alemã, implantaram por lei a participação dos trabalhadores na direção das emprèsas. Sem chegar a esse ponto, é inegável nos demais países a tendência a uma maior promoção e valorização do trabalho humano no processo produtivo e a uma maior integração dos trabalhadores nas emprêsas (v. Alvaro Garrada Valcarcer, La Participacion de los Trabaja- 
dores en la Direccion de las Empresas en Alemania, Oviedo, 1967).

Merece ser lembrado, a respeito, o documentado livro do saudoso publicista Paulo Nogueira Filho, sôbre a autogestão da emprêsa, o qual contem valiosos elementos para o estudo do assunto. Refere-se NogueIra FilHo às tendências reformistas na França, que se orientam também no sentido da participação dos tecnocratas e dos trabalhadores na administração das emprêsas (v. Françors Bloch-Lainé, Pour une réforme de l'entreprise, 1963).

c) - A elaboração do conceito da função social da propriedade dos meios de produção da emprêsa, acarretando não só limitações, mas também deveres positivos para com a coletividade por parte de seus proprietários.

Não hesita Ballerstedt em afirmar que o direito de propriedade sôbre os bens de produção é mais restrito do que o exercido sôbre bens de consumo. Essa distinção é apoiada pela moderna doutrina; na França por Josserand, na Itália por Pugliatti e Rosario Nicolò, entre nós por Or-LANDo Gomes, para só citar alguns nomes. Nessa linha de idéias, a emprêsa (e, por conseqüência, a sociedade anônima) seria uma forma de exercício da propriedade dos bens de produção.

Estas considerações, embora. sugestivas e estimulantes no plano sociológico, apresentam uma perspectiva mais “ideal" do que "real" da sociedade anônima atual.

Valem, contudo, para evidenciar as tendências reformistas que se observam mesmo em países de patronato tradicionalista como o francês.

Não obstante possam inspirar a política legislativa na elaboração do direito futuro, tais concepções ainda não encontram clima para aplicação imediata em nosso país, no quadro do sistema jurídico vigente. 
A reforma da S. A. brasileira.

Numerosos e variados são os problemas que a sociedade anônima, como tipo mais expressivo de organização empresarial, suscita em nosso país. Diversos pontos "quentes" são debatidos com vistas à projetada reforma das anônimas, variando a profundidade das alterações propostas segundo a posição doutrinária de seus proponentes. Há mesmo quem negue a oportunidade de qualquer modificação no regime legal do anonimato.

Dentro de uma posição neo-liberal, que se funda precìpuamente na afirmação das virtudes da livre emprêsa, e que é a posição adotada pelos órgãos mais representativos do empresariado nacional, podemos encontrar a média das opiniões traduzida nas conclusões aprovadas pelo Simpósio há pouco realizado em São Paulo, sob o patrocínio da Federação das Indústrias e com a participação de numerosas entidades. As recomendações formuladas caracterizamse pela objetividade e ausência de conotações ideológicas extremadas, filtrando sugestões que visam ùnicamente ao aprimoramento de nossa legislação no contexto do sistema vigente.

A idéia-matriz que norteia tôda a sistemática da reforma projetada é a de que o caminho certo para a integração da emprêsa na comunidade é o da "socialização consentida", mediante a abertura do seu capital à participação do público em geral.

O reconhecimento desta verdade não deve, porém, levar ao exagêro de procurar deslocar a tônica da normatividade da sociedade por ações para a regulamentação do mercado de capitais. O mercado de capitais é simples conseqüência da sociedade anônima, pois existe em função das necessidades de financiamento das atividades produtoras. 
Confluem na sociedade anônima interêsses e motivações que nem sempre são homogêneos e conciliáveis. Devese, na medida do possível, estabelecer um justo equilíbrio entre os interêsses da emprêsa e os interêsses da coletividade, esta representada sobretudo pelo mercado de capitais. A proteção dispensada aos investidores não deve, contudo, ir ao ponto de entravar o normal funcionamento da sociedade anônima, em virtude da excessiva burocratização.

Não se justifica que a mesma estrutura jurídica e as mesmas normas legais se apliquem, indistintamente, às companhias de grande envergadura, que têm por objetivo a exploração de setôres básicos da economia e que recorrem comumente ao mercado de capitais, e às pequenas sociedades fechadas, de âmbito familiar ou restrito a pequeno grupo de pessoas, sòmente pelo fato, que lhes é comum, de terem o capital social dividido em ações.

Deveria ser prevista em nossa lei, dentro do quadro geral das sociedades por ações, a exemplo de outras legislações, uma estrutura simplificada para a pequena sociedade anônima, em vista do seu diminuto capital e exíguo número de acionistas.

A lei inglêsa (Companies Act de 1948, seção 28) disciplina as chamadas private companies, constituídas por subscrição particular, que são isentas de uma série de formalidades e exigências legais e nas quais é limitado o número de acionistas a cinqüenta, excluídos os empregados. O art. 90 do Código de Comércio holandês regulamenta as sociedades anônimas ditas fechadas, em que as decisões dos acionistas são tomadas independentemente da realização de assembléia.

Talvez uma adequada reformulação da legislação sôbre as sociedades por qüotas de responsabilidade limitada pudesse atender a êsse escôpo, ensejando a transforma- 
ção nesse tipo societário de numerosas emprêsas, a grande maioria das que são hoje organizadas sob a forma do anonimato. Enquanto isto não ocorra, deverá a lei prever regime jurídico diferenciado para as sociedades anônimas, de modo a distinguir perfeitamente as sociedades grandes ou abertas, e as pequenas ou fechadas.

As grandes companhias, ou sociedades anônimas pròpriamente ditas, seriam caracterizadas: pela faculdade de recorrer à subscrição pública; por terem seus títulos obrigatòriamente registrados para negociação em Bôlsa; pela fixação de capital mínimo; pela existência do Conselho de Administração.

As sociedades pequenas ou fechadas, ao contrário, não poderiam recorrer à subscrição pública dos seus títulos, nem tê-los registrados para negociação em Bôlsa; não lhes seria exigida a publicação, em jornais, de seus balanços, nem estipulado o capital mínimo; mas, em contrapartida, não poderiam emitir debêntures ou mesmo ações ao portador.

A distinção, já estabelecida em lei para efeitos tributários, entre as sociedades anônimas de capital aberto e as de capital fechado atende à realidade sócio-econômica. Interessa mais de perto à economia pública o contrôle preventivo das emprêsas que lançam títulos à subscrição pública, motivo pelo qual se justificam plenamente os mecanismos legais de tutela aos subscritores. Já o mesmo não ocorre com as emprêsas que, adotando a veste legal da sociedade anônima, interessam na sua constituição e funcionamento a um número restrito de acionistas. Daí a inteira procedência da acenada distinção.

Nas grandes sociedades, os diretores detêm um poder decisório considerável, que não é suficientemente controlado ou limitado pela assembléia geral dos acionistas.

Nas legislações estrangeiras (norte-americana, alemã, francesa) é prevista uma organização administrativa que permita representação mais eficiente dos vários grupos de interêsses em presença. Assim, é facultada a criação de 
um Conselho de Administração, formado de acionistas eleitos pela Assembléia Geral, com representação obrigatória das minorias acionárias. Compete ao Conselho de Administração não só nomear e destituir os Diretores Executivos, como também fiscalizar sua gestão, em tudo o que não seja o exame dos livros e papéis contábeis da sociedade, bem assim autorizar a alienação ou oneração dos bens sociais, acima de certa percentagem do capital social.

A criação dêsse nôvo modêlo de organização administrativa possibilitaria a implantação da gerência técnica assalariada, ao nivel da Diretoria Executiva, enquanto que o contrôle da gestão seria exercido pelos representantes dos acionistas com assento no Conselho de Administração.

A experiência tem revelado a ocorrência de intoleráveis descomedimentos e abusos no tocante à remuneração dos diretores. Deve ser estabelecida pela lei uma limitação da remuneração variável dos administradores da sociedade anônima, fixando-a em determinado percentual dos dividendos distribuídos.

No capítulo da tutela dos direitos dos subscritores, é axiomático que a intervenção das emprêsas do mercado de capitais na oferta pública de subscrição inicial ou de aumento de capital deve levar ao fortalecimento da confiança do público nos papéis-valor, diminuindo ou eliminando a possibilidade de ilaqueação da bôa fé dos subscritores ou compradores.

Nessa conformidade, normas legais tornando obrigatório o registro das sociedades emissoras de ações ou debêntures na Bôlsa de Valores de sua séde, bem assim a intervenção das sociedades autorizadas a operar no sistema de distribuição do mercado de capitais na oferta pública de subscrição inicial de capital ou seu aumento, constituem medidas altamente recomendáveis.

O direito do acionista ao dividendo constitui tema controvertido, que tem ensejado o choque do interêsse da 
emprêsa e da maioria com a proteção da minoria de acionistas. É inegável, no entanto, que a falta de defesa do acionista minoritário contra as práticas abusivas da maioria, no tocante à distribuição dos lucros, constitui um embaraço para a simpatia do investidor potencial, ao passo que, assegurando-se o pagamento mais firme do dividendo anual, maior prestígio seria atribuido aos investimentos em ações. Daí o nosso aplauso a que se assegure ao acionista a faculdade de retirar-se da sociedade, mediante o reembôlso do valor contábil de suas ações, se, durante um período de três anos consecutivos, sem motivo justo e comprovado, não forem distribuídos os dividendos mínimos de $6 \%$ (seis por cento) ao ano.

Ainda com o objetivo de reprimir os abusos do auto-financiamento, deve-se assegurar às ações preferenciais o direito ao pagamento de um dividendo fixo mínimo de 6\% (seis por cento), vedando-se à assembléia geral, antes de sua distribuição, o destaque de qualquer parcela do lucro líquido, apurado em balanço, para a constituição de fundos de reserva facultativos.

A fim de coibir práticas fraudatórias atinentes à integralizaçãa do valor das ações subscritas por meio de títulos cambiários, convém que disponha a lei que só possam elas ser negociadas após realizados trinta por cento do seu valor nominal, permanecendo nominativas até o efetivo resgate dêsses títulos.

No que concerne ao regime jurídico dos títulos sociais, uma questão que tem sido objeto de acirrado debate diz respeito à legitimidade da emissão de ações com ágio. Essa prática se justifica, a fim de que os acionistas antigos não sofram com a diluição do valor de suas ações, que a emissão ao par necessàriamente acarreta, nem que novos acionistas se beneficiem injustamente com o valor efetivo das ações antigas. Para evitar distorções, deve ser imposta à emprêsa a obrigação de constituir reserva específica com o resultado, enquanto não fôr incorporada ao capital da 
sociedade, vedada a cobrança de ágio que efetivamente não correspon la à diferença entre o valor nominal e o valor real das ações.

Outro fator que se tem revelado prejudicial à distribuição de dividendos aos acionistas é a criação de partes beneficiárias. Convinhável seria que a lei fixasse o máximo dedutível do lucro líquido para formação do fundo de resgate, estabelecesse o valor máximo de resgate e a limitação do prazo para a validade das partes beneficiárias.

Vários outros pontos de interêsse, como os pertinentes ao funcionamento da assembléia geral, ao direito de informação do acionista e à auditoria contábil independente, poderiam ser objeto de nossas cogitações.

Para não alongar a exposição, todavia, vamos cuidar somente de mais dois aspectos que se nos afiguram relevantes, na sistemática das sociedades anônimas.

Um dêles diz respeito aos chamados grupos societários, ainda não regulados em nosso direito, formados em decorrência da coligação inler-societária ou do contrôle exercido por uma sociedade sôbre outra.

Embora não sejam condenáveis a priori, é certo que os grupos societários podem dar margem a abusos $\mathrm{e}$ distorções no que se refere à autenticidade do capital das sociedades integrantes do mesmo grupo. A fim de resguardar o princípio básico da intangibilidade do capital social, a lei deveria proibir que as sociedades invistam o seu próprio capital em ações da sociedade que exerce o seu contrôle sôbre ela, ou de outras sociedades pela mesma controladas (como dispõe o art. 2359 do Código Civil Italiano).

Do mesmo modo, deveria a lei proibir a constituição ou aumento de capital das sociedades mediante subscrição recíproca de ações, mesmo por interposta pessoa. E que a 
sociedade anônima de cujo capital participe, com mais de $10 \%$ (dez por cento), outra sociedade, possa por sua vez participar do capital desta.

Seria útil, no estágio atual de nossa economia, que se regulassem em lei o consórcio de emprêsas e os chamados contratos inter-empresariais (contratos de dominação e de transferência de lucros), com base na experiência do direito comparado.

Outro problema importante é o atinente ao critério aferidor da nacionalidade da sociedade anônima.

A tradição jurídica nacional, consubstanciada no artigo 60 da vigente lei de sociedades por ações (decreto-lei $n .^{\circ}$ 2.627 , de 1940), adota o critério de organização da sociedade segundo a lei brasileira e manutenção no país de sua séde efetiva. Outra corrente preconiza a modificação no sentido de ser adotado o critério do chamado "contrôle acionário", que até agora tem sido invocado sòmente em circunstâncias excepcionais e em setôres de especial interêsse para a economia ou soberania nacional. Uma tomada de posição nêste último sentido envolveria sérias restrições aos investimentos estrangeiros no país, pelo que deveria ser apreciada à luz de uma análise realista das vantagens ou desvantagens que poderia acarretar à economia brasileira.

Muito haveria ainda que dizer, pois o tema é fascinante e pràticamente inexaurível.

Nosso objetivo foi o de salientar o papel singular que está reservado às sociedades anônimas, no processo do desenvolvimento econômico e no contexto social e político. Faz-se mister conhecer os novos rumos que marcam a evolução do instituto em outros países para aplicar as lições hauridas da ciência e da experiência ao caso brasileiro. Afinal, é do estudo e da meditação que deverão surgir as soluções para mais êste complexo problema: a reforma da sociedade anônima no Brasil. 